\title{
Designing ICT to Support Positive Ageing in Saudi Arabia
}

Soud Nassir

Faculty of Engineering and IT

University of Technology Sydney

Broadway, NSW 2009, Australia

soud.a.nassir@student.uts.edu.au

\section{Abstract}

In recent years, some $\mathrm{HCI}$ researchers (e.g., Durick et al. 2013 and Light et al 2015) pointed out that a dominant approach in ICT design for the aged is led by deficit models of ageing people; viewing the aged as a homogenous group of frail, needy, and passive people who are incapable of learning/using new ICTs. My research seeks to counter this dominant approach by focusing upon ways to design information and communication technologies (ICT) to support older people in Saudi Arabia to age-well.

Permission to make digital or hard copies of part or all of this work for personal or classroom use is granted without fee provided that copies are not made or distributed for profit or commercial advantage and that copies bear this notice and the full citation on the first page. Copyrights copies bear this notice and the full citation on the first page. Copyrights
for third-party components of this work must be honored. For all other uses, contact the Owner/Author.

Copyright is held by the owner/author(s).

DIS '16 Companion, June 04-08, 2016, Brisbane, QLD, Australia ACM 978-1-4503-4315-2/16/06.

http://dx.doi.org/10.1145/2908805.2909426
The positive approach I adopt will be grounded upon a more balanced picture of ageing people; looking at ageing as a process and describing it in terms of success, productivity, active participation and quality of life. Through this, I hope to offer approaches to ICT design that can support ageing people's independence and agency as they age.

\section{Author Keywords}

Ageing; design; positive ageing; Saudi Arabia.

\section{ACM Classification Keywords}

H.5.m. Information interfaces and presentation (e.g. $\mathrm{HCI}$ ): Miscellaneous.

\section{Positive Ageing}

There are a number of positive ageing models and frameworks, each reflecting particular discipline-specific approaches, funding bodies and assumptions about older people and their ageing experiences. I spent the first year of my research, going through the positive ageing literature, distilling elements and factors from a range of frameworks, in order to build a holistic picture of what are considered to be important to enable, support and/or extend ageing-well. A summary of the findings was published [see (Nassir et al. 2015)].

My review led to a realization that current positive ageing frameworks offer a western-centric perception 
of ageing. This reveals a gap in our current understandings of ageing in non-western cultures, including Saudi Arabia, in particular with regards to the considerations of local culture, gender, religion and how aged people are cared for. For example, supporting 'independence' whereby people can thrive on their own may need to be considered differently in Saudi Arabia. Culturally, strong familial intergenerational dependencies mean that ageing people prefer and are expected to live with their kin. This expect financial support and care, be it from a familial or non-familial informal carer (e.g. hired maids). Older women's agency in Saudi Arabia is different from women in the West and their experience of ageing will be different. That is why understanding the influences of local culture on ageing through contextualised fieldwork in local settings is paramount to technology design for ageing people in Saudi Arabia.

\section{Approach}

This research aims to develop insights into how older adults experience ageing in Saudi Arabia including their aspirations, values and particular situations. I will use open-ended interviews, probe activities and a series of participatory design workshop to help deepen and broaden current understandings of ageing, inform design approaches and identify opportunities for ICT interventions that can support older Saudis to age-well and improve their quality of life. Furthermore, the study aims to generate design tools, approaches, knowledge and guidelines for designers that aim to support positive ageing in this local context. However, conducting fieldwork in a culturally-sensitive setting can be challenging. For example, female participants may need to be accompanied by a chaperon to interviews which may influence their feedback, while the workshops are likely to be segregated by gender and run with the help of a female facilitator. Utilizing probes in this context may help reduce external influences, while allowing me the opportunity to elicit participants' ideas, thoughts and values. I will need to consider how I design probe activities, since about $57 \%$ of older Saudis are illiterate. I am currently designing, piloting and conducting the interviews and probes, which will require a degree of translation and consideration of relevant culture and local contexts. I expect to finish this task by June (the time of the conference).

I seek opportunities to discuss such challenges received feedback and learn from an experienced pane and fellow researchers. I am particularly interested in getting advice with regards to how I might collect data and how PD workshops can be prepared and conducted in such culturally-sensitive settings.

\section{References}

1. Ann Light, Tuck Wah Leong, Toni Robertson. 2015. Ageing well with CSCW. In Proceedings of the 14th European Conference on Computer Supported Cooperative Work (ECSCW), 295-304. https://doi.org/10.1007/978-3-319-20499-4_16

2. Jeannette Durick, Toni Robertson, Margot Brereton, Frank Vetere and Bjorn Nansen. 2013. Dispelling ageing myths in technology design. In Proceedings of the Annual Meeting of the Australian SIGCHI (OzCHI'13), 467-476. http://doi.org/10.1145/2541016.2541040

3. Soud Nassir, Tuck Wah Leong and Toni Robertson. 2015. Positive Ageing: Elements and factors for design. In Proceedings of the Annual Meeting of the Australian SIGCHI (OzCHI'15), 264-268. http://doi.org/10.1145/2838739.2838796 